\title{
A neuropsychological profile for agenesis of the corpus callosum? Cognitive, academic, executive, social and behavioral functioning in school-age children
}

\begin{tabular}{|c|c|}
\hline Journal: & Journal of the International Neuropsychological S \\
\hline Manuscript ID & JINS\#-17-RR-108.R2 \\
\hline Manuscript Type: & Regular Research \\
\hline Date Submitted by the Author: & $n / a$ \\
\hline Complete List of Authors: & $\begin{array}{l}\text { Siffredi, Vanessa; University of Geneva, Laboratory for Behavioral } \\
\text { Neurology and Imaging of Cognition; Murdoch Childrens Research } \\
\text { Institute, Clinical Sciences Research; The University of Melbourne, School } \\
\text { of Psychological Sciences } \\
\text { Anderson, Vicki; Murdoch Childrens Research Institute, Clinical Sciences } \\
\text { Research; Royal Children's Hospital Melbourne, Department of Psychology; } \\
\text { The University of Melbourne, School of Psychological Sciences; The } \\
\text { University of Melbourne, Department of Paediatrics } \\
\text { McIlroy, Alissandra; Murdoch Childrens Research Institute, Clinical } \\
\text { Sciences Research } \\
\text { Wood, Amanda; Murdoch Childrens Research Institute, Clinical Sciences } \\
\text { Research; Aston University, School of Life and Health Sciences } \\
\text { Leventer, Richard; Murdoch Childrens Research Institute, Neuroscience } \\
\text { Research Group; Royal Children's Hospital Melbourne, Department of } \\
\text { Neurology; The University of Melbourne, Department of Paediatrics } \\
\text { Spencer-Smith, Megan; Monash University, School of Psychological } \\
\text { Sciences and Monash Institute of Cognitive and Clinical Neurosciences; } \\
\text { Murdoch Childrens Research Institute, Clinical Sciences Research }\end{array}$ \\
\hline MeSH Keywords: & $\begin{array}{l}\text { agenesis of the corpus callosum, congenital brain malformation, } \\
\text { neuropsychological outcomes, pediatrics, cognitive functions, socio- } \\
\text { behavioral functions }\end{array}$ \\
\hline Topic Areas: & $\begin{array}{l}\text { Neurological Disorders- Other, Congenital/Genetic Disorders, } \\
\text { Developmental and Learning Disorders, Children \& Developmental } \\
\text { Disorders, Cognitive Science, Corpus Callosum }\end{array}$ \\
\hline
\end{tabular}


Dear Prof E Mark Mahone,

Re: A neuropsychological profile for agenesis of the corpus callosum? Cognitive, academic, executive, social and behavioral functioning in school-age children JINS\#-17RR-108

Thank you for accepting our manuscript for publication with minor revisions.

We would like to thank again the reviewers for their positive and constructive comments.

Below we provide responses to each reviewer comment. The associated amendments in the manuscript are highlighted in red (and the amendments related to the previous revisions are highlighted in yellow).

Best wishes,

Dr Vanessa Siffredi and Dr Megan Spencer-Smith

\section{Reviewer 1}

Comment: The authors have been very responsive to feedback provided by the Reviewers and Action Editor. I have no further suggestions for revision.

Response: Thank you.

\section{Reviewer 2}

Comment: You have been very diligent in responding to the questions I raised in my earlier review—-thank you!

\section{Response: Thank you.}

Comment: My only lingering concern is whether this report will be really useful, and to whom. The heterogeneity of callosal agenesis both behaviorally and genetically makes it difficult to use the data with reference to particular individuals, although suppose the study can at least indicate the likely range of presentation. You suggest that heterogeneity is a positive feature, although even the heterogeneity is limited given the source of the data. Even so, this study is perhaps a useful contrast with the Quebec studies, where there was relative homogeneity, especially genetically.

Response: This report provides crucial information for clinicians (neonatologists, neurologists, and neuropsychologists) and families on what to expect from a cognitive point of view in children and adolescents with $\mathrm{AgCC}$ who present to clinical attention. It also provides insight into risk and protective factors.

Comment: From my perspective, the most useful observation was the even distribution of handedness, ignored in the first version and skipped over here. There is quite a lot of evidence that handedness is random in the absence of any congenital bias, and the data now seem to 
suggest that it is indeed random among those with agenesis of the corpus callosum. Could this mean that handedness itself depends on normal development of the corpus callosum? To me at least, this is something that does need further comment.

Response: In the general population, the percentage of left-handedness is around 10 to $13 \%$ (Raymond, Pontier, Dufour, Moller, 1996). We observed a much higher percentage of lefthanders in our paediatric AgCC cohort, consistent with previous AgCC studies. For example, $50 \%$ of AgCC participants were left-handed or ambidextrous in the Lábadi \& Beke (2017) study, 56\% in the Sauerwein \& Lassonde (1994) study, 24\% in the Sauerwein et al. (1993) study, 24\% in the Chiarello (1980) study. This atypical high percentage of left-handedness in $\mathrm{AgCC}$ samples could indeed reflect processes associated with the early development of the corpus callosum and lateralisation of hemispheric function. We have added references of previous AgCC studies reporting high rates of left-handedness, and made this point in the Discussion section on page 15 paragraph 1:

"Consistent with previous AgCC studies that have reported a higher proportion of lefthanders than in the general population, ranging from $24 \%$ to $56 \%$ (e.g., Lábadi \& Beke, 2017; Sauerwein \& Lassonde, 1994; Chiarello, 1980), in our AgCC cohort almost half of the children were left-handed. This atypical clinical observation might reflect properties of this brain malformation. It is possible that process associated with the early development of the corpus callosum and early development of lateralization of hemispheric function in general play a role in determining handedness."

\section{Reviewer 3}

Comment: I am satisfied with the revised version of the manuscript.

Response: Thank you. 
Siffredi - Neuropsychological outcomes in callosal agenesis

\section{A neuropsychological profile for agenesis of the corpus callosum? Cognitive, academic, executive, social and behavioral functioning in school-age children}

Vanessa Siffredi, ${ }^{1,2,3}$ Vicki Anderson, ${ }^{2,3,4,5}$ Alissandra Mcllroy, ${ }^{2}$ Amanda G. Wood, ${ }^{2,6}$ Richard J. Leventer, ${ }^{4,7,8}$ Megan M. Spencer-Smith ${ }^{2,9}$

${ }^{1}$ Laboratory for Behavioral Neurology and Imaging of Cognition, University of Geneva, Switzerland

${ }^{2}$ Clinical Sciences Research, Murdoch Children’s Research Institute, Melbourne, Australia

${ }^{3}$ School of Psychological Sciences, University of Melbourne, Melbourne, Australia

${ }^{4}$ Department of Paediatrics, University of Melbourne, Melbourne, Australia

${ }^{5}$ Department of Psychology, Royal Children's Hospital, Melbourne, Australia

${ }^{6}$ School of Life and Health Sciences, Aston University, United-Kingdom

${ }^{7}$ Department of Neurology, Royal Children's Hospital, Melbourne, Australia

${ }^{8}$ Neuroscience Research Group, Murdoch Children's Research Institute, Melbourne, Australia

${ }^{9}$ School of Psychological Sciences and Monash Institute of Cognitive and Clinical Neurosciences, Monash University, Melbourne, Australia

Corresponding author: Megan Spencer-Smith, $\mathrm{PhD}$

School of Psychological Sciences and Monash Institute of Cognitive and Clinical Neurosciences Monash University, 18 Innovation Walk, Clayton Campus, Clayton VIC 3800, Australia megan.spencer-smith@monash.edu, +61 399059148

Abstract - word count: 256

Manuscript - word count: 4320 
Siffredi - Neuropsychological outcomes in callosal agenesis

\section{ABSTRACT}

Objective: Agenesis of the corpus callosum $(\mathrm{AgCC})$, characterized by developmental absence of the corpus callosum, is one of the most common congenital brain malformations. To date, there are limited data on the neuropsychological consequences of $\mathrm{AgCC}$ and factors that modulate different outcomes, especially in children. This study aimed to describe general intellectual, academic, executive, social and behavioral functioning in a cohort of school-aged children presenting for clinical services to a hospital and diagnosed with AgCC. The influences of age, social risk and neurological factors were examined.

Method: 28 school-aged children (8 to 17 years) diagnosed with $\mathrm{AgCC}$ completed tests of general intelligence (IQ) and academic functioning. Executive, social and behavioral functioning in daily life, and social risk, were estimated from parent and teacher rated questionnaires. MRI findings reviewed by a pediatric neurologist confirmed diagnosis and identified brain characteristics. Clinical details including the presence of epilepsy and diagnosed genetic condition were obtained from medical records.

Results: In our cohort, $\sim 50 \%$ of children experienced general intellectual, academic, executive, social and/or behavioral difficulties and $\sim 20 \%$ were functioning at a level comparable to typically developing children. Social risk was important for understanding variability in neuropsychological outcomes. Brain anomalies and complete AgCC were associated with lower mathematics performance and poorer executive functioning.

Conclusions: This is the first comprehensive report of general intellectual, academic, executive social and behavioral consequences of $\mathrm{AgCC}$ in school-aged children. The findings have important clinical implications, suggesting that support to families and targeted intervention could promote positive neuropsychological functioning in children with $\mathrm{AgCC}$ who come to clinical attention.

Keywords: agenesis of the corpus callosum; congenital brain malformation; neuropsychological outcomes; pediatrics; cognitive functions; socio-behavioral functions. 
Siffredi - Neuropsychological outcomes in callosal agenesis

\section{Introduction}

With over 190 million axons, the corpus callosum (CC) is the largest brain white matter pathway and connects homologous structures in the left and right cerebral hemispheres (Paul et al., 2007). Developmental absence of the CC, or Agenesis of the Corpus Callosum (AgCC), is amongst the most common brain malformations observed in humans, with an estimated prevalence of 1 to 7 per 4000 live births (Glass, Shaw, Ma, \& Sherr, 2008). Diagnosis is based on brain imaging including prenatal ultrasound and postnatal neuroimaging and can be complete or partial, see Figure $1 . \mathrm{AgCC}$ may occur as an isolated malformation or can be associated with other brain malformations or multiple congenital anomaly syndromes. It can result from environmental, metabolic or genetic causes (Edwards, Sherr, Barkovich, \& Richards, 2014).

\section{[INSERT FIGURE 1 HERE]}

Consistent with the variability in presentation and etiology of this brain malformation, previous studies have reported cognitive abilities ranging from "normal", with children attending mainstream school and adults having a conventional career (Caillé et al., 1999), to severe cognitive difficulties, with individuals attending special developmental school and requiring assistance in daily living activities (Graham et al., 2008; Graham et al., 2003). Initial studies of individuals with AgCC reported a pattern of reduced performance across multiple cognitive domains (Chiarello, 1980; Lassonde \& Jeeves, 1994; Sauerwein \& Lassonde, 1994). However, these study samples collapsed across children and adults, and had specific selection criteria (e.g. IQ >70). Further, participants were not routinely diagnosed based on MRI scan, which may have impacted diagnostic accuracy (e.g. diagnosis based on CT may lead to hypoplasia being incorrectly diagnosed as AgCC) (Sauerwein \& Lassonde, 1994). In a systematic review of neuropsychological functioning in AgCC, where diagnosis was based on MRI ( $\mathrm{n}=110$ patients), intellectual functioning was described to be, on average, in the low average range for adults (IQ: Mean=88.2, $\mathrm{SD}=15.18, \mathrm{n}=41$ ) and significantly 
Siffredi - Neuropsychological outcomes in callosal agenesis

lower for children (IQ: Mean=76.4, $\mathrm{SD}=30.12, \mathrm{n}=48$; Siffredi, Anderson, Leventer, \& SpencerSmith, 2013). Qualitative examination highlighted that individuals (adults and children) with AgCC are at particular risk of impaired arithmetic skills, with $86 \%$ demonstrating impairments. In contrast, executive functions, reading and spelling skills were relatively preserved. Studies examining social functioning in individuals with $\mathrm{AgCC}$ report a range of impairments, such as reduced understanding of jokes and humor (Brown, Paul, Symington, \& Dietrich, 2005), proverb and non-literal items (Paul, Van Lancker-Sidtis, Schieffer, Dietrich, \& Brown, 2003), complex social scenes (Brown \& Paul, 2000; Paul, Schieffer, \& Brown, 2004; Turk, Brown, Symington, \& Paul, 2010), integration of social information from multiple sources (e.g., paralinguistic cues, nonliteral language; Symington, Paul, Symington, Ono, \& Brown, 2010), story-generation skills (Paul et al., 2004), and difficulties experiencing and thinking about complex but not basic emotions in the context of social interactions (L. B. Anderson, Paul, \& Brown, 2017). Links between AgCC and autism spectrum disorder (ASD) symptoms have also been examined, but results have been mixed. In a convenience sample of 189 children and adults with $\mathrm{AgCC}, 8.5 \%$ met criteria for ASD diagnosis (vs. $1 \%$ of their siblings; Doherty, Tu, Schilmoeller, \& Schilmoeller, 2006) while in a more recent convenience sample of 26 individuals with $\mathrm{AgCC}$, eight $(30.8 \%)$ were reported as having autism symptoms but only 3 of 22 (13.6\%) met criteria for an ASD diagnosis (Paul, Corsello, Kennedy, \& Adolphs, 2014).

Numerous factors are likely to influence neuropsychological development in children with AgCC, as outlined by Maureen Dennis and colleagues $(2000,2006)$ in their developmental framework. Age is important for understanding level of cognitive functioning, and in $\mathrm{AgCC}$ better general intellectual function have been observed in adults compared with children (Siffredi et al., 2013). Social factors, including demographic characteristics and family function, can influence a child's neuropsychological development (Hackman \& Farah, 2009; Sirin, 2005). Neurological factors should also be considered in understanding neuropsychological outcomes in this atypically 
Siffredi - Neuropsychological outcomes in callosal agenesis

developing brain. In the context of $\mathrm{AgCC}$, some of the neurological factors that might influence outcomes include clinical co-morbidities (e.g., additional central nervous system (CNS) anomalies) or the presence of seizures, and associated genetic conditions (Dennis et al., 2006). Some genetic conditions, such as Aicardi syndrome, are uniformly associated with AgCC, and single gene disorders (e.g., Edwards et al., 2014; Palmer \& Mowat, 2014) and multiple chromosomal abnormalities associated with AgCC have also been described (D'Antonio et al. 2016). Recently the first gene for isolated AgCC, DCC, was identified (Marsh et al., 2017). The genetic etiology may also be polygenic and/or reflect complex genetic interactions (Paul et al. 2007). Several studies suggest that isolated AgCC appears to carry the best prognosis, with up to $85 \%$ of individuals exhibiting average cognitive functioning (Pilu et al., 1993; Vergani et al., 1994). A number of potential candidates for compensation have been suggested, in particular enlargement of the anterior and posterior commissures, as well as the degree of $\mathrm{AgCC}$ (partial or complete). Enlargement (hyperplasia) of the anterior commissure, found in about $10 \%$ of individuals with $\mathrm{AgCC}$ (Hetts, Sherr, Chao, Gobuty, \& Barkovich, 2006; Loeser \& Alvord, 1968) and enlargement of posterior commissure might be indicators of CC fibers using these commissures as alternative interhemispheric conduits (Hannay, Dennis, Kramer, Blaser, \& Fletcher, 2009). Similarly, the degree of AgCC (complete or partial) could differentially allow white matter fibers to cross the midline, and therefore increase the presence of interhemispheric functional connections (HuberOkrainec, Blaser, \& Dennis, 2005).

Currently our understanding of the consequences of $\mathrm{AgCC}$ for school-age children on neuropsychological functioning and factors that modulate the consequences of $\mathrm{AgCC}$ on these functions is restricted by the inherent problem of small sample studies and conflicting results (Bedeschi et al., 2006; D'Antonio et al., 2016; Moutard et al., 2003; Shevell, 2002). The challenge of studying the high heterogeneity of this population has previously been addressed by focusing on individuals with isolated AgCC only, which does not reflect the AgCC population. A detailed MR- 
Siffredi - Neuropsychological outcomes in callosal agenesis

based study of 82 patients with AgCC showed that it was truly isolated in only $4 \%$ of patients, with most having additional brain abnormalities such as cortical malformations (Hetts et al., 2006). Clinicians therefore lack the necessary knowledge to provide the families of children with AgCC the information regarding prognosis or optimal intervention targets. This study aimed to describe general intellectual, academic, executive, social and behavioral functioning in a large cohort of school-aged children who presented for clinical services to a hospital and diagnosed with AgCC. The influence of age, social risk and neurological factors on neuropsychological functioning was examined. Patients included both those with isolated $\mathrm{AgCC}$ and $\mathrm{AgCC}$ associated with other brain malformations. This study represents a first step in providing an understanding of the neuropsychological profile of children with AgCC. 
Siffredi - Neuropsychological outcomes in callosal agenesis

\section{METHOD}

\section{Sample}

Our AgCC cohort was recruited as part of the "Paediatric Agenesis of the Corpus Callosum Project" at the Murdoch Children's Research Institute in Melbourne, Australia. Twenty-eight participants ( $85 \%$ of those eligible, $\mathrm{n}=33)$, aged 8 to 17 years $(\mathrm{M}=11.54, \mathrm{SD}=2.35)$ were ascertained by review of the radiology database at The Royal Children's Hospital $(\mathrm{RCH})$, see Figure 2 for participant flow. Inclusion criteria were: 1) aged 8.0 to 16.11 years at recruitment between September 2009 and February 2014; 2) evidence of AgCC on MRI; 3) English speaking; and 4) ability to engage in neuropsychological testing. $37 \%$ of children who were screened for inclusion in the study were excluded due to severe impairment and inability to engage in neuropsychological testing but otherwise met inclusion criteria.

\section{[INSERT FIGURE 2 HERE]}

\section{Procedure}

The RCH Human Research Ethics Committee approved the study. Caregivers, and when appropriate participants (based on age), provided informed written consent before participation. Participants completed a neuropsychological assessment and MRI, or gave consent to use previous clinical MRI scans. Caregivers and teachers completed questionnaires.

\section{Measures}

\section{Neuropsychological functioning:}

Child testing was conducted by a training child psychologist (MSS, AM, VS under supervision by VA) using standardized tests to estimate: 1) General intelligence: Full Scale, Verbal and Performance IQ $(M=100, S D=15)$ were generated from the four subtest version of the Wechsler Abbreviated Intelligence Scale (WASI: Wechsler, 1999, $\mathrm{n}=21,75 \%$ ) or the Wechsler Intelligence 
Siffredi - Neuropsychological outcomes in callosal agenesis

Scale for Children, 4th edition (WISC-IV: Wechsler, $2003 \mathrm{n}=7,25 \%$ ) based on 10 subtests. 2) Academic functioning: The Wide Range Achievement Test 4 (WRAT-4: Wilkinson \& Robertson, 2006) was administered to estimate: single Word Reading, Spelling and Math Computation $(\mathrm{M}=100, \mathrm{SD}=15)$.

Parents and teachers completed age standardized questionnaires to estimate: 3) Executive function in everyday life: The Behavioral Rating Inventory of Executive Function: parent form (BRIEF: Gioia, Isquith, Guy, \& Kenworthy, 2000) estimates executive abilities in everyday life over the past 6 month. It generates two summary index scales: Behavioral Regulation Index (BRI: based on Inhibit, Shift and Emotional control subscales) and Metacognition Index (MCI: based on Initiate, Working memory, Plan/organize, Organization of materials and Monitor subscales); as well as a Global Executive Composite (GEC) based on both indices. Higher scores reflect increased difficulties in executive functioning $(\mathrm{M}=50, \mathrm{SD}=10)$. 4) Behavior: Strengths and Difficulties Questionnaire (SDQ; Goodman, 1997) generates a Total Difficulties score estimating general behavioral and emotional functioning over the past 6 months (based on the subscales Emotional Symptoms, Conduct Symptoms, Hyperactivity-Inattention and Peer Problems). Australian test norms were used (Mellor, 2005). 5) Social function: Social Skills Improvement System (SSIS; Gresham \& Elliott, 2008) estimated aspects of social functioning. It generates the Social Skills scale and the Problem Behavior scale, including the Autism Spectrum subscale that estimates ASD behaviors. A higher score on the Social Skills scale indicates better social functioning and a lower score on the Problem Behavior scale indicates better behavioral functioning $(M=100, S D=15)$.

\section{Risk Factors:}

1) Age at testing. 2) Social risk: estimated using the Social Risk Index, a composite score based on information collected from a caregiver questionnaire: family structure, education of primary caregiver, occupation of primary income earner, employment status of primary income earner, 
Siffredi - Neuropsychological outcomes in callosal agenesis

language spoken at home, and maternal age at birth. Scores range from $0-12$, with higher scores representing higher socio-economical risk (Roberts et al., 2008). 3) Neurological factors: Structural MR images acquired on 3T Siemens Magnetom Trio Scanner using a 32-channel head coil $\left(\mathrm{TR}=1900 \mathrm{~ms}, \mathrm{TE}=2.71 \mathrm{~ms}, \mathrm{TI}=900 \mathrm{~ms}, \mathrm{FA}=9^{\circ}, \mathrm{FoV}=256 \mathrm{~mm}\right.$ and voxel size $\left.=0.7 \times 0.7 \times 0.7 \mathrm{~mm}\right)$ were qualitatively reviewed by a pediatric neurologist with expertise in brain malformations (RJL). A specially modified protocol (V. Anderson et al., 2009; Leventer et al., 1999) was employed to characterize $\mathrm{AgCC}$ and associated CNS anomalies: (a) AgCC type: $\mathrm{AgCC}$ was classified as partial $=\mathrm{a}$ section of the corpus callosum absent, or complete $=$ the entire corpus callosum absent; (b) anterior and posterior commissures: were classified as absent, reduced, normal or enlarged; (c) CNS anomalies: additional to the $\mathrm{AgCC}$ were classified as absent or present (excluding common concomitant anatomical changes due to the absence (complete or partial) of the $\mathrm{CC}$ such as Probst bundles, cingulate gyrus alteration and colpocephaly; Booth, Wallace, \& Happe, 2011; Lee, Kim, Cho, \& Lee, 2004; Paul, 2011; Paul et al., 2007). Based on medical records and parent interview, (d) diagnosed genetic condition: classified as present or absent and (d) seizure disorder: classified as present or absent.

\section{Developmental delay:}

Caregivers completed a structured interview that elicited information on when the child reached developmental milestones and was used to estimate whether the child had a developmental delay. The child was classified as having a motor delay if they achieved the milestones of rolling after 6 months, crawling after 9 months, and walking after 15 months; and a speech delay if they achieved the milestone of speaking single words after 15 months and speaking sentences of 2 to 3 words after 24 months.

\section{Statistical Analyses}


Siffredi - Neuropsychological outcomes in callosal agenesis

To examine differences between the AgCC group mean scores and test norms, one-sample t-test or Wilcoxon signed-rank test in the case of violation of normality was used. Mean differences in test scores within each functional domain were examined using paired-sample t-test or Wilcoxon signed-rank test. Based on previous studies reporting on individuals with AgCC and the developmental framework of Dennis $(2000,2006)$, backward hierarchical regressions were used as an exploratory model building method to examine associations between risk factors as predictors and neuropsychological functions as outcomes. The order in which predictors were entered into the model was guided by Dennis' framework: 1) age at testing; 2) social risk index; and 3) neurological factors, including AgCC type (complete vs partial), size of the anterior and of the posterior commissures (absent, reduced, normal or enlarged), additional CNS anomalies (present or absent), diagnosed genetic condition, presence of a seizure disorder. The default stepping criteria of $p<.05$ was used for inclusion and for removal of variables in the models. To address Type II Error, Bonferroni correction for multiple comparisons (Field, 2013) was applied to the resulting regression models: $\alpha$ altered $=\alpha$ original $0.05 / 8$ comparisons $=0.006$. 
Siffredi - Neuropsychological outcomes in callosal agenesis

\section{RESULTS}

\section{Sample characteristics}

Table 1 presents the characteristics of our pediatric $\mathrm{AgCC}$ cohort $(\mathrm{n}=28)$, which included more males than females. Half of the cohort was right-handed, almost just as many were left-handed, and a small number showed mixed handedness. There were similar proportions of children with complete $\operatorname{AgCC}(n=14)$ and partial $\operatorname{AgCC}(n=14)$. There were fewer children with isolated $\operatorname{AgCC}$ $(n=11)$ and more children with AgCC associated with other CNS anomalies $(n=17)$ in our cohort. Table 1 highlights the heterogeneity in clinical presentation of children with AgCC. The supplementary table provides details of individuals' clinical characteristics.

\section{[INSERT TABLE 1 HERE]}

\section{AgCC neuropsychological functioning compared with normative expectations}

Children with $\mathrm{AgCC}$ achieved poorer scores than the normative test mean on all neuropsychological measures, see Table 2. For general intellectual functioning, mean scores were in the borderline range for Full-Scale IQ and Verbal IQ, and higher, in the low average range, for Performance IQ. The overall distribution for each IQ indices was skewed toward the lower end of population expectations. The majority of children (46.4 to $66.7 \%$ ) were categorized with a mild impairment for intellectual functions. For academic functioning, mean scores were in the borderline range for Math Computation, and the low average range for Word Reading and Spelling. For Word Reading and Spelling, about half of the children performed in the average range or above, with impairments in Math Computation more frequent. For executive functioning in daily life, mean parent and teacher ratings on BRIEF indices were in the clinical range, with the exception of the parent rated Behavioral Regulation Index, which was in the borderline range. For behavioral functioning, mean ratings on the SDQ Total Difficulties score (parent and teacher) were above the average range $(+1 \mathrm{SD})$. For social functioning, mean parent and teacher ratings on the SISS scales were in the low 
Siffredi - Neuropsychological outcomes in callosal agenesis

average (parent ratings) to average (teacher ratings) range for the Social Skills scale, and in the average range for the Problem Behaviors scale. Of interest, a significant level of autism spectrum behaviors was reported in more than half of the sample by both parents $(61.9 \%)$ and teachers $(55.6 \%)$.

\section{[INSERT TABLE 2 HERE]}

\section{Pattern of functioning within neuropsychological domains}

There were some significant within group comparisons for select neuropsychological domains examined. For general intellectual functioning, Performance IQ was significantly better than Verbal IQ, $t(26)=3.245, p=.003$. For academic functioning, Word Reading, $t(24)=-5.221, p<.001$, and Spelling $\mathrm{t}(25)=-3.063, \mathrm{p}=.005$ were significantly better than Math Computation. For executive functioning in daily life, the parent-rated Behavioral Regulation Index was better than Metacognition Index, $\mathrm{t}(27)=-2.093, \mathrm{p}=.046$.

\section{Risk factors associated with neuropsychological functioning}

Analyses revealed that some risk factors were important predictors for specific aspects of neuropsychological functioning, even after Bonferroni correction $(\mathrm{p}<.006)$, Table 3. For academic functioning, higher Social Risk Index and complete AgCC were associated with poorer Word Reading scores, together accounting for $36.2 \%$ of the variance, while higher Social Risk Index and additional CNS anomalies were associated with poorer Math Computation scores, accounting for $44.2 \%$ of the variance. For executive functioning in daily life, higher Social Risk Index, complete $\mathrm{AgCC}$ and older age at testing were associated with poorer parent ratings on the BRIEF Behavior Regulation Index and Global Executive Composite, accounting for $38.6 \%$ and $35.4 \%$ of the variance respectively, while higher Social Risk Index was associated with poorer parent ratings on the BRIEF Metacognition Index, accounting for $25.9 \%$ of the variance. For behavioral functioning, 
Siffredi - Neuropsychological outcomes in callosal agenesis

higher Social Risk Index was associated with poorer parent ratings on SDQ Total Difficulties, accounting for $55.5 \%$ of the variance, while additional CNS anomalies were associated with poorer teacher ratings on SDQ Total Difficulties, accounting for $45.3 \%$ of variance.

[INSERT TABLE 3 HERE] 
Siffredi - Neuropsychological outcomes in callosal agenesis

\section{DISCUSSION}

A major congenital brain malformation such as $\mathrm{AgCC}$ demonstrates the remarkable capacity of the brain for structural and functional plasticity during development. Indeed, individuals with AgCC do not exhibit the classic disconnection syndrome observed in "split-brain" patients, where absence of the $\mathrm{CC}$ is acquired through surgical resection for the treatment of epilepsy. Consequences of developmental absence of the CC remain imperfectly understood, largely reflecting the inherent problem of small sample studies and the important heterogeneity of this population in terms of neuroimaging profiles (complete or partial, isolated or associated AgCC), etiologies, neuropsychological difficulties, and clinical sequelae (Bedeschi et al., 2006; D'Antonio et al., 2016; Moutard et al., 2003; Shevell, 2002; Siffredi et al., 2017). This study provides the first comprehensive report of general intellectual, academic, executive, behavioral and social functioning in a cohort of school-age children presenting for clinical services to a hospital and diagnosed with AgCC confirmed on MRI.

Our pediatric cohort performed below normative test expectations across all neuropsychological domains studied. However, it is important to note that, despite major atypical brain development, around $20 \%$ performed at the average or above average level of functioning across all domains. Overall, general intellectual functioning in our $\mathrm{AgCC}$ cohort was in the borderline range, and more than one standard deviation below the average test mean for the general population. As often reported in previous AgCC studies, we observed a significant variability within our pediatric cohort, with Full-Scale IQ ranging from extremely low to superior. The distributions for both verbal and performance IQs were skewed toward the lower end of the normal distribution. Consistent with low general intellectual functioning in our cohort and previous child and adolescent $\mathrm{AgCC}$ studies (Siffredi et al., 2013), we observed high rates of parent-reported developmental delays, with $32 \%$ of children reported to have had speech delay and $46 \%$ motor delay. Our results reveal stronger visualspatial than verbal abilities, a result that is specific to our cohort and might reflect the inherent 
Siffredi - Neuropsychological outcomes in callosal agenesis

heterogeneity of AgCC. For academic functioning, mathematical performance was most impaired, falling in the borderline range, with reading and spelling both in the low average range. This is consistent with previous studies showing high rates of mathematical impairment (Siffredi et al., 2013). In regards to educational placement, more children attended mainstream school in earlier school levels, while in later school levels it was more common for children to attend special developmental school. Almost half of the children attending secondary school were attending special developmental school, while, in contrast, most of the remaining participants were reported by parents as performing at an average level at least in mainstream school (with or without the support of additional tutoring or aid). For executive functioning in daily life, children demonstrated more difficulties in metacognition (e.g., working memory, initiation) than behavioral regulation (e.g., inhibition, emotional control). Significant behavioral and social difficulties were observed in our cohort, consistent with previous studies. Furthermore, a high rate of ASD symptoms was observed, with more than half of parents and teachers reporting clinical levels of ASD in our cohort (Paul et al., 2014; Paul et al., 2004). Consistent with previous AgCC studies that have reported a higher proportion of left-handers than in the general population, ranging from $24 \%$ to $56 \%$ (e.g., Lábadi \& Beke, 2017; Sauerwein \& Lassonde, 1994; Chiarello, 1980), in our AgCC cohort almost half of the children were left-handed. This atypical clinical observation might reflect properties of this brain malformation. It is possible that processes associated with the early development of the corpus callosum and early development of lateralization of hemispheric function in general play a role in determining handedness.

In our cohort of children with $\mathrm{AgCC}$, we found social risk was a key factor in understanding functioning across academic, executive and behavioral domains, but not intellectual or social functionin domains. In typically developing children, the association between high social risk and low achievement in academic functioning, in particular mathematics, as well as low executive and 
Siffredi - Neuropsychological outcomes in callosal agenesis

behavioral functioning has been well documented (Farah et al., 2006; Jordan \& Levine, 2009; Sarsour et al., 2011). This importance of social risk for understanding variability in functional outcomes for children with AgCC is consistent with Dennis' developmental framework (2000, 2006) proposing factors likely to influence neuropsychological development. However, in contrast to this framework, we found little evidence that the child's age at testing or a wide range of neurological factors proposed in the literature to influence neuropsychological functioning, including AgCC type, size of the anterior and posterior commissures, additional CNS anomalies, diagnosed genetic condition or seizure disorder, were consistently associated with functioning across intellectual, academic, executive, behavioral and social domains. We note, there was some suggestion that the presence of additional CNS anomalies was associated with select aspects of academic, executive, behavior and social functioning, and complete $\mathrm{AgCC}$ was associated with aspects of academic and executive functioning. Future studies examining age, social risk and neurological factors associated with neuropsychological functioning in larger samples will be important.

The findings of this study should be considered in the context of its limitations. Due to our inclusion criterion for children to have the ability to engage in testing, we acknowledge that our cohort likely represents higher functioning $\mathrm{AgCC}$ children (see Figure 2 for participant flow). However, it is also possible our cohort is biased toward individuals with sufficient clinical need for referral for brain scan (only $35.7 \%$ were diagnosed prenatally). Given the rapid advances in neuroimaging, including ultrasound, and its growing use in obstetric populations, increased detection of patients with AgCC during fetal life through routine ultrasound screening, including those who are asymptomatic, may result in research documenting alternative profiles of neuropsychological functioning to those that exists in the historical literature (Pisani, Bianchi, Piantelli, Gramellini, \& Bevilacqua, 2006). Moreover, we used a subjective method for reviewing MRI scans to describe neurological characteristics, in particular properties of the anterior and 
Siffredi - Neuropsychological outcomes in callosal agenesis

posterior commissures that could be involved in compensation mechanisms in individuals with AgCC (Barr \& Corballis, 2002; Hannay et al., 2009; Lassonde, Sauerwein, Chicoine, \& Geoffroy, 1991). The use of quantitative measures could provide new insights into compensation mechanisms in this population, such as volumetric or quality of the fibers crossing these commissures, to explore associations with neuropsychological outcomes. The use of test norms rather than a local representative comparison group of children, and the small sample of children across a relatively wide age range with a range of varying etiologies and brain abnormalities on MRI are limitations that should be considered. This study provides a broad understanding of neuropsychological functioning in children with $\mathrm{AgCC}$ presenting for clinical services, and future studies examining in further detail neuropsychological domains will contribute to a greater understanding of neuropsychological outcomes.

\section{Conclusion}

To our knowledge, this is the first cohort study to comprehensively report on general intellectual, academic, executive, behavioral and social consequences of AgCC in school-age children who present for clinical services to a hospital. We showed that while children with AgCC perform below their peers across a range of neuropsychological domains, they demonstrate some relative strengths within domains. Specifically, we identified relative strengths in non-verbal skills, word reading, spelling, and everyday behavioral regulation. Our results do not support a clear and unique neuropsychological phenotype for $\mathrm{AgCC}$ in childhood, further highlighting the heterogeneity of this condition. The variability in neuropsychological functioning we observed appears to be differentially associated with individual factors, in particular social risk. These findings have important clinical implications, suggesting that providing children and their families with a supportive social environment could promote positive neuropsychological outcomes across a range of domains, for example through school support and aid, parenting advice, access to tailored 
Siffredi - Neuropsychological outcomes in callosal agenesis

interventions according to the child's individual difficulties such as psychological, speech or occupational interventions. Further research in a larger cohort of patients with AgCC is needed to better understand the neuropsychological outcomes in this heterogeneous population.

\section{ACKNOWLEDGEMENTS}

We gratefully thank Kate Pope for her assistance in recruitment, the radiographers at Melbourne Children's MRI Centre and Dr Marc Seal for his support, as well as the families who participated in this study. This study was supported by Victorian Government's Operational Infrastructure Support Program, and the Murdoch Childrens Research Institute and the Alain Patry Grant from the Geneva Academic Society. Dr Vanessa Siffredi was supported by the Swiss National Science Foundation Doc.CH scholarship. Professor Vicki Anderson was supported by Australian National Health and Medical Research Council Senior Practitioner Fellowship. The authors have no conflict of interest and no competing financial interests to disclose.

\section{REFERENCES}

Anderson, L. B., Paul, L. K., \& Brown, W. S. (2017). Emotional Intelligence in Agenesis of the Corpus Callosum. Arch Clin Neuropsychol, 32(3), 267-279. doi: 10.1093/arclin/acx001

Anderson, V., Spencer-Smith, M., Leventer, R., Coleman, L., Anderson, P., Williams, J., . . . Jacobs, R. (2009). Childhood brain insult: can age at insult help us predict outcome? Brain, 132(Pt 1), 45-56. doi: 10.1093/brain/awn293

Barr, Melodie S., \& Corballis, Michael C. (2002). The role of the anterior commissure in callosal agenesis. Neuropsychology, 16(4), 459-471. doi: 10.1037/0894-4105.16.4.459

Bedeschi, M. F., Bonaglia, M. C., Grasso, R., Pellegri, A., Garghentino, R. R., Battaglia, M. A., .. . Borgatti, R. (2006). Agenesis of the corpus callosum: clinical and genetic study in 63 young patients. Pediatr Neurol, 34(3), 186-193.

Booth, R., Wallace, G. L., \& Happe, F. (2011). Connectivity and the corpus callosum in autism spectrum conditions: Insights from comparison of autism and callosal agenesis. Gene Expression to Neurobiology and Behavior: Human Brain Development and Developmental Disorders, 189, 303-317. doi: Doi 10.1016/B978-0-444-53884-0.00031-2

Brown, W. S., \& Paul, L. K. (2000). Cognitive and psychosocial deficits in agenesis of the corpus callosum with normal intelligence. Cognitive Neuropsychiatry, 5(2), 135-157. doi: $10.1080 / 135468000395781$ 
Siffredi - Neuropsychological outcomes in callosal agenesis

Brown, W. S., Paul, L. K., Symington, M., \& Dietrich, R. (2005). Comprehension of humor in primary agenesis of the corpus callosum. Neuropsychologia, 43(6), 906-916. doi: 10.1016/j.neuropsychologia.2004.09.008

Caillé, S., Schiavetto, A., Andermann, F., Bastos, A., de Guise, E., \& Lassonde, M. (1999). Interhemispheric transfer without forebrain commissures. Neurocase, 5(2), 109-118. doi: 10.1093/neucas/5.2.109

Chiarello, C. (1980). A house divided? Cognitive functioning with callosal agenesis. Brain Lang, 11(1), 128-158. doi: 10.1016/0093-934x(80)90116-9

D'Antonio, F., Pagani, G., Familiari, A., Khalil, A., Sagies, T. L., Malinger, G., . . Prefumo, F. (2016). Outcomes Associated With Isolated Agenesis of the Corpus Callosum: A Metaanalysis. Pediatrics, 138(3). doi: 10.1542/peds.2016-0445

Dennis, M. (2000). Developmental plasticity in children: the role of biological risk, development, time, and reserve. J Commun Disord, 33(4), 321-331; quiz 332.

Dennis, M., Yeates, K., Taylor, H., \& Fletcher, J. (2006). Brain reserve capacity, cognitive reserve capacity, and age-based functional plasticity after congenital and acquired brain injury in children. London and New York: Taylor \& Francis.

Edwards, T. J., Sherr, E. H., Barkovich, A. J., \& Richards, L. J. (2014). Clinical, genetic and imaging findings identify new causes for corpus callosum development syndromes. Brain, 137(Pt 6), 1579-1613. doi: 10.1093/brain/awt358

Farah, M. J., Shera, D. M., Savage, J. H., Betancourt, L., Giannetta, J. M., Brodsky, N. L., ... Hurt, H. (2006). Childhood poverty: specific associations with neurocognitive development. Brain Res, 1110(1), 166-174. doi: 10.1016/j.brainres.2006.06.072

Field, Andy P. (2013). Discovering statistics using IBM SPSS statistics : and sex and drugs and rock' $n$ ' roll (4th edition. ed.).

Gioia, G. A., Isquith, P. K., Guy, S. C., \& Kenworthy, L. (2000). Behavior rating inventory of executive function. Odessa, FL: Psychological Assessment Resources.

Glass, H. C., Shaw, G. M., Ma, C., \& Sherr, E. H. (2008). Agenesis of the corpus callosum in California 1983-2003: a population-based study. Am J Med Genet A, 146A(19), 2495-2500.

Goodman, R. (1997). The Strengths and Difficulties Questionnaire: a research note. J Child Psychol Psychiatry, 38(5), 581-586.

Graham, John M., Jr., Visootsak, Jeannie, Dykens, Elisabeth, Huddleston, Lillie, Clark, Robin D., Jones, Kenneth L., . . . Stevenson, Roger E. (2008). Behavior of 10 patients with FG syndrome (Opitz-Kaveggia syndrome) and the p.R961 W mutation in the MED12 gene. Am J Med Genet A, 146A(23), 3011-3017.

Graham, John M., Jr., Wheeler, Patricia, Tackels-Horne, Darci, Lin, Angela E., Hall, Bryan D., May, Melanie, ... Cox, Timothy C. (2003). A new X-linked syndrome with agenesis of the corpus callosum, mental retardation, coloboma, micrognathia, and a mutation in the Alpha 4 gene at Xq13. Am J Med Genet A, 123A(1), 37-44.

Gresham, F. M., \& Elliott, S. N. (2008). Social Skills Improvement System Rating Scales manual. Minneapolis, MN: NCS Pearson.

Groen, M. A., Whitehouse, A. J., Badcock, N. A., \& Bishop, D. V. (2012). Does cerebral lateralization develop? A study using functional transcranial Doppler ultrasound assessing lateralization for language production and visuospatial memory. Brain Behav, 2(3), 256269. doi: $10.1002 /$ brb3.56

Hackman, D. A., \& Farah, M. J. (2009). Socioeconomic status and the developing brain. Trends Cogn Sci, 13(2), 65-73. doi: 10.1016/j.tics.2008.11.003

Hannay, H. J., Dennis, M., Kramer, L., Blaser, S., \& Fletcher, J. M. (2009). Partial agenesis of the corpus callosum in spina bifida meningomyelocele and potential compensatory mechanisms. J Clin Exp Neuropsychol, 31(2), 180-194.

Hetts, S. W., Sherr, E. H., Chao, S., Gobuty, S., \& Barkovich, A. J. (2006). Anomalies of the corpus callosum: an MR analysis of the phenotypic spectrum of associated malformations. American Journal of Roentgenology, 187, 1343-1348. 
Siffredi - Neuropsychological outcomes in callosal agenesis

Huber-Okrainec, Joelene, Blaser, Susan E., \& Dennis, Maureen. (2005). Idiom comprehension deficits in relation to corpus callosum agenesis and hypoplasia in children with spina bifida meningomyelocele. Brain Lang, 93(3), 349-368.

Jordan, N. C., \& Levine, S. C. (2009). Socioeconomic variation, number competence, and mathematics learning difficulties in young children. Dev Disabil Res Rev, 15(1), 60-68. doi: $10.1002 /$ ddrr.46

Labadi, B., \& Beke, A. M. (2017). Mental State Understanding in Children with Agenesis of the Corpus Callosum. Front Psychol, 8, 94. doi: 10.3389/fpsyg.2017.00094

Lassonde, M., \& Jeeves, M. A. (1994). Callosal agenesis: A natural split brain? New York, NY US: Plenum Press.

Lassonde, M., Sauerwein, H., Chicoine, A. J., \& Geoffroy, G. (1991). Absence of disconnexion syndrome in callosal agenesis and early callosotomy: brain reorganization or lack of structural specificity during ontogeny? Neuropsychologia, 29(6), 481-495.

Lee, Seung Woo, Kim, Kwang Soo, Cho, Sung Min, \& Lee, Sun Joo. (2004). An atypical case of Aicardi syndrome with favorable outcome. Korean Journal Of Ophthalmology: KJO, 18(1), 79-83.

Leventer, R. J., Phelan, E. M., Coleman, L. T., Kean, M. J., Jackson, G. D., \& Harvey, A. S. (1999). Clinical and imaging features of cortical malformations in childhood. Neurology, 53(4), 715-722.

Loeser, J. D., \& Alvord, E. C., Jr. (1968). Clinicopathological correlations in agenesis of the corpus callosum. Neurology, 18(8), 745-756.

Marsh, A. P., Heron, D., Edwards, T. J., Quartier, A., Galea, C., Nava, C., . . Depienne, C. (2017). Mutations in DCC cause isolated agenesis of the corpus callosum with incomplete penetrance. Nat Genet, 49(4), 511-514. doi: 10.1038/ng.3794

Mellor, D. (2005). Normative data for the Strengths and Difficulties Questionnaire in Australia. Australian Psychologist, 40(3), 215-222. doi: 10.1080/00050060500243475

Moutard, M. L., Kieffer, V., Feingold, J., Kieffer, F., Lewin, F., Adamsbaum, C., . . Ponsot, G. (2003). Agenesis of corpus callosum: prenatal diagnosis and prognosis. Child's Nervous System: Chns: Official Journal Of The International Society For Pediatric Neurosurgery, 19(7-8), 471-476.

Oldfield, R. C. (1971). The assessment and analysis of handedness: the Edinburgh inventory. Neuropsychologia, 9(1), 97-113.

Paul, L. K. (2011). Developmental malformation of the corpus callosum: a review of typical callosal development and examples of developmental disorders with callosal involvement. $J$ Neurodev Disord, 3(1), 3-27. doi: 10.1007/s11689-010-9059-y

Paul, L. K., Brown, W. S., Adolphs, R., Tyszka, J. M., Richards, L. J., Mukherjee, P., \& Sherr, E. H. (2007). Agenesis of the corpus callosum: genetic, developmental and functional aspects of connectivity. Nat Rev Neurosci, 8(4), 287-299.

Paul, L. K., Corsello, C., Kennedy, D. P., \& Adolphs, R. (2014). Agenesis of the corpus callosum and autism: a comprehensive comparison. Brain, 137( $\mathrm{Pt} 6)$, 1813-1829. doi: 10.1093/brain/awu070

Paul, L. K., Schieffer, B., \& Brown, W. S. (2004). Social processing deficits in agenesis of the corpus callosum: narratives from the Thematic Appreciation Test. Archives Of Clinical Neuropsychology: The Official Journal Of The National Academy Of Neuropsychologists, 19(2), 215-225.

Paul, L. K., Van Lancker-Sidtis, D., Schieffer, B., Dietrich, R., \& Brown, W. S. (2003). Communicative deficits in agenesis of the corpus callosum: nonliteral language and affective prosody. Brain Lang, 85(2), 313-324.

Pilu, G., Sandri, F., Perolo, A., Pittalis, M. C., Grisolia, G., Cocchi, G., . . . Bovicelli, L. (1993). Sonography of fetal agenesis of the corpus callosum: a survey of 35 cases. Ultrasound Obstet Gynecol, 3(5), 318-329. doi: 10.1046/j.1469-0705.1993.03050318.x 
Siffredi - Neuropsychological outcomes in callosal agenesis

Pisani, F., Bianchi, M. E., Piantelli, G., Gramellini, D., \& Bevilacqua, G. (2006). Prenatal diagnosis of agenesis of corpus callosum: what is the neurodevelopmental outcome? Pediatrics International: Official Journal Of The Japan Pediatric Society, 48(3), 298-304.

Roberts, G., Howard, K., Spittle, A. J., Brown, N. C., Anderson, P. J., \& Doyle, L. W. (2008). Rates of early intervention services in very preterm children with developmental disabilities at age 2 years. J Paediatr Child Health, 44(5), 276-280. doi: 10.1111/j.1440-1754.2007.01251.x

Sarsour, K., Sheridan, M., Jutte, D., Nuru-Jeter, A., Hinshaw, S., \& Boyce, W. T. (2011). Family socioeconomic status and child executive functions: the roles of language, home environment, and single parenthood. J Int Neuropsychol Soc, 17(1), 120-132. doi: $10.1017 / \mathrm{S} 1355617710001335$

Sauerwein, H. C., \& Lassonde, M. (1994). Cognitive and sensori-motor functioning in the absence of the corpus callosum: neuropsychological studies in callosal agenesis and callosotomized patients. Behav Brain Res, 64(1-2), 229-240.

Shevell, Michael I. (2002). Clinical and diagnostic profile of agenesis of the corpus callosum. $J$ Child Neurol, 17(12), 896-900.

Siffredi, V., Anderson, V., Leventer, R. J., \& Spencer-Smith, M. M. (2013). Neuropsychological profile of agenesis of the corpus callosum: a systematic review. Dev Neuropsychol, 38(1), 36-57. doi: 10.1080/87565641.2012.721421

Siffredi, V., Spencer-Smith, M. M., Barrouillet, P., Vaessen, M. J., Leventer, R. J., Anderson, V., \& Vuilleumier, P. (2017). Neural correlates of working memory in children and adolescents with agenesis of the corpus callosum: An fMRI study. Neuropsychologia, 106, 71-82. doi: 10.1016/j.neuropsychologia.2017.09.008

Sirin, S. R. (2005). Socioeconomic status and academic achievement: A meta-analytic review of research. Review of Educational Research, 75(3), 417-453. doi: Doi 10.3102/00346543075003417

Symington, S. H., Paul, L. K., Symington, M. F., Ono, M., \& Brown, W. S. (2010). Social cognition in individuals with agenesis of the corpus callosum. Soc Neurosci, 5(3), 296-308. doi: Pii 919286264

Doi 10.1080/17470910903462419

Turk, A. A., Brown, W. S., Symington, M., \& Paul, L. K. (2010). Social narratives in agenesis of the corpus callosum: linguistic analysis of the Thematic Apperception Test. Neuropsychologia, 48(1), 43-50. doi: 10.1016/j.neuropsychologia.2009.08.009

Vergani, P., Ghidini, A., Strobelt, N., Locatelli, A., Mariani, S., Bertalero, C., \& Cavallone, M. (1994). Prognostic indicators in the prenatal diagnosis of agenesis of corpus callosum. Am J Obstet Gynecol, 170(3), 753-758.

Wechsler, D. (1999). Wechsler Abbreviated Scale of Intelligence (WASI). San Antonio, TX: Psychological Corporation.

Wechsler, D. (2003). Manual for the Wechsler Intelligence Scale for Children-IV. New York: Psychological Corporation.

Wilkinson, G. S., \& Robertson, G. J. (2006). Wide Range Achievement Test 4, Professional manual. Lutz, FL: Psychological Assessment Resources. 
Siffredi - Neuropsychological outcomes in callosal agenesis 


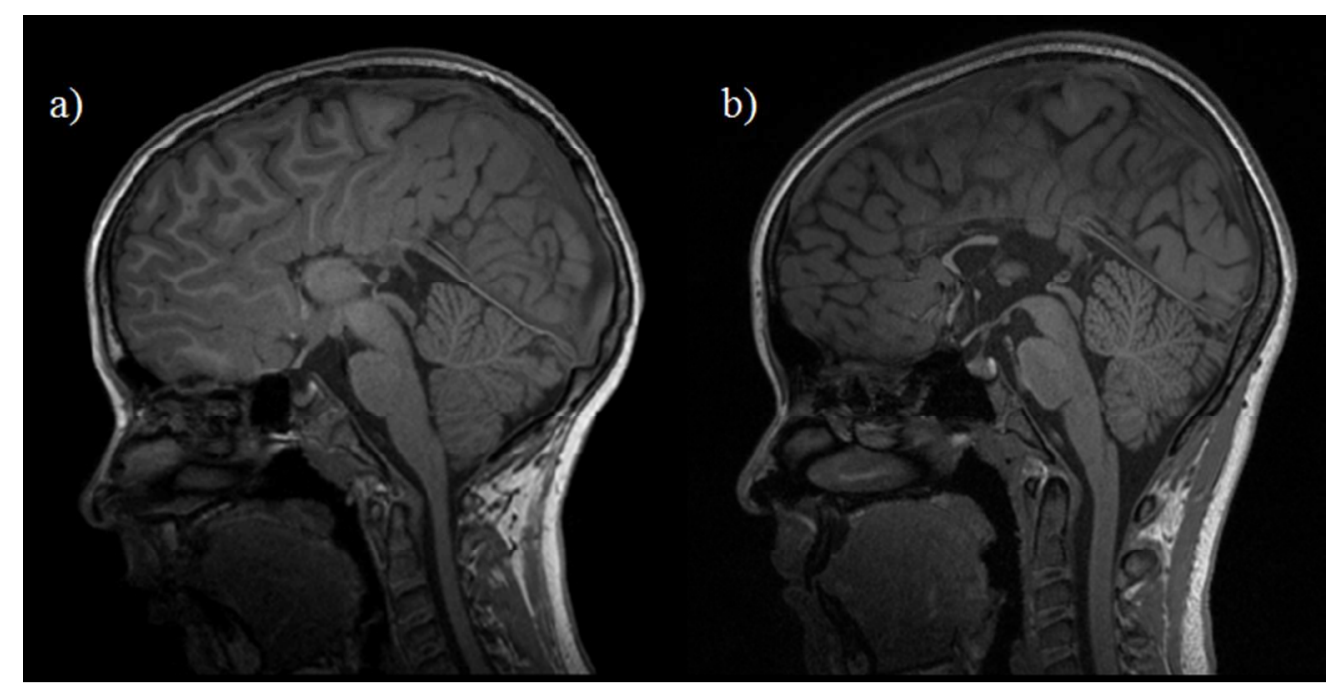

Figure 1. Midsagittal T1-weighted MRI of a) complete; and b) partial AgCC 
Patients presented at the Royal Children's Hospital between 1.1 .98 and 31.12 .2008

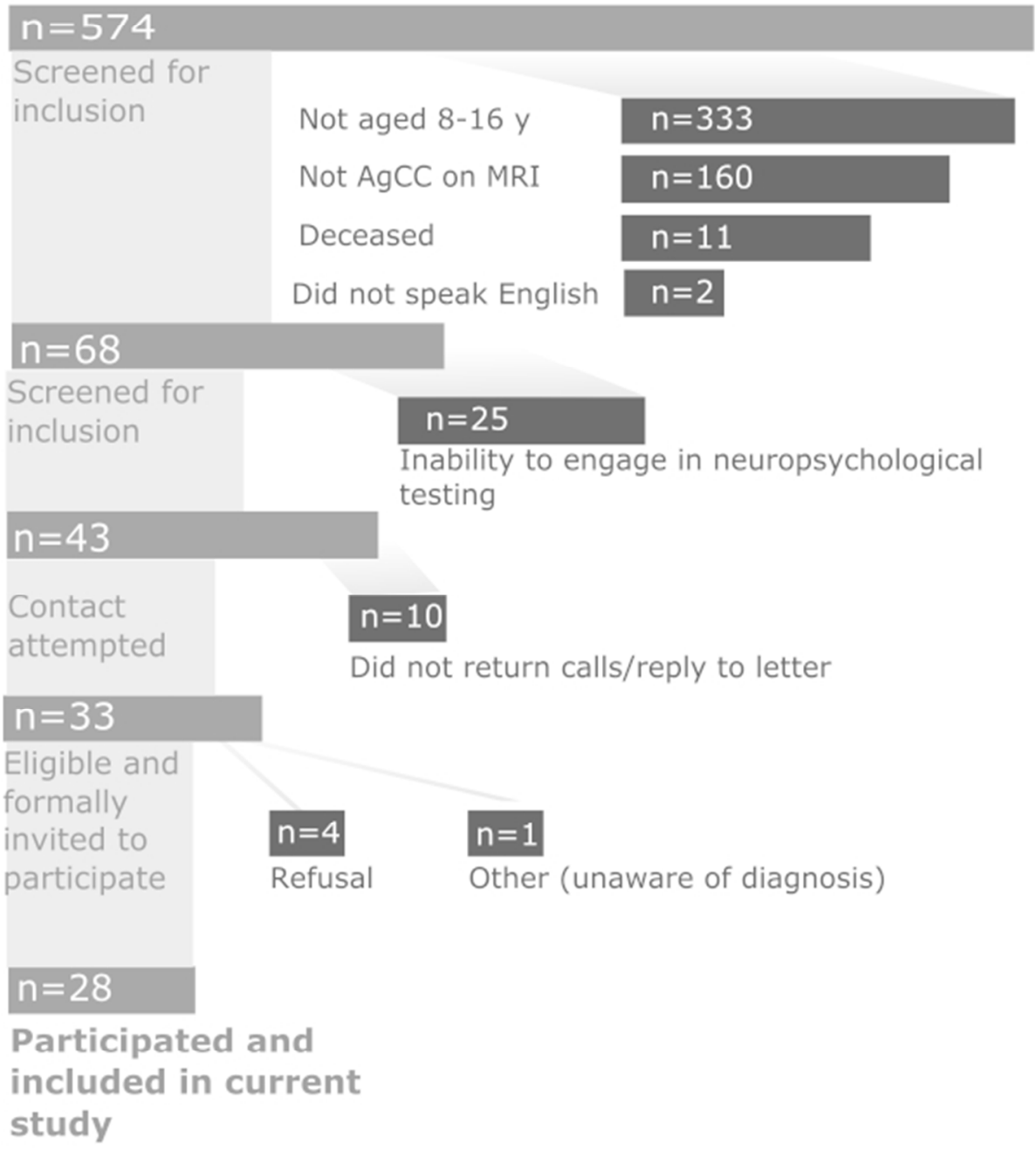

Figure 2. Flow chart of of study recruitment process 
Table 2. Neuropsychological functioning of the Pediatric Agenesis of the Corpus Callosum Cohort: comparison with normative test means, and impairment rates

\begin{tabular}{|c|c|c|c|c|c|c|c|c|c|}
\hline & \multicolumn{2}{|c|}{ AgCC cohort } & \multirow{2}{*}{$\begin{array}{l}\text { Normative } \\
\text { Test } \\
\text { M (SD) }\end{array}$} & \multirow[t]{2}{*}{$\begin{array}{l}\text { Mean } \\
\text { difference }\end{array}$} & \multicolumn{2}{|c|}{$\begin{array}{l}\text { One sample t or Wilcoxon } \\
\text { signed-rank tests }\end{array}$} & \multicolumn{3}{|c|}{ Percentage impaired } \\
\hline & $\mathbf{n}$ & M (SD) or Mdn & & & $t(d f)$ or $Z$ & p value & $\begin{array}{l}\text { Average } \\
\text { or above }\end{array}$ & Mild & $\begin{array}{l}\text { Moderate } \\
\text { to severe }\end{array}$ \\
\hline \multicolumn{10}{|c|}{ General intellectual functioning (WASI or WISC-IV) } \\
\hline Full-Scale IQ & 27 & $\begin{array}{l}78.3(15.21) \\
\mathrm{Mdn}=74\end{array}$ & $100(15)$ & -21.7 & $Z=12.5$ & $<.001$ & 18.5 & 66.7 & 14.8 \\
\hline Verbal IQ & 27 & $76.37(13.45)$ & $100(15)$ & -23.63 & $t(26)=-9.13$ & $<.001$ & 29.6 & 48.2 & 22.2 \\
\hline Performance IQ & 28 & $84(18.19)$ & $100(15)$ & -16 & $t(27)=-4.65$ & $<.001$ & 39.3 & 46.4 & 14.3 \\
\hline \multicolumn{10}{|c|}{ Academic functioning (WRAT-4) } \\
\hline Word Reading & 25 & $89.04(20.21)$ & $100(15)$ & -10.96 & $\mathrm{t}(24)=-2.71$ & .012 & 56 & 24 & 20 \\
\hline Spelling & 26 & $83.46(18.27)$ & $100(15)$ & -16.54 & $t(25)=-4.62$ & $<.001$ & 46.2 & 30.7 & 23.1 \\
\hline Math Computation & 27 & $76.04(13.94)$ & $100(15)$ & -23.96 & $t(26)=-8.93$ & $<.001$ & 25.9 & 40.8 & 33.3 \\
\hline \multicolumn{10}{|c|}{ Executive functioning in daily life, parent ratings (BRIEF) } \\
\hline Global Executive Composite & 28 & $\begin{array}{l}68.07(11.91) \\
\mathrm{Mdn}=65\end{array}$ & $50(10)$ & +18.07 & $Z=404$ & $<.001$ & 21.4 & 50 & 28.6 \\
\hline Behavior Regulation Index & 28 & $\begin{array}{l}64.82(14.25) \\
\mathrm{Mdn}=61\end{array}$ & $50(10)$ & +14.82 & $Z=343$ & $<.001$ & 42.9 & 28.5 & 28.6 \\
\hline Metacognition Index & 28 & $68.29(10.26)$ & $50(10)$ & +18.29 & $\mathrm{t}(27)=9.4$ & $<.001$ & 17.9 & 50 & 32.1 \\
\hline \multicolumn{10}{|c|}{ Executive functioning in daily life, teacher ratings (BRIEF) } \\
\hline Global Executive Composite & 17 & $71.12(13.6)$ & $50(10)$ & +21.12 & $\mathrm{t}(16)=6.4$ & $<.001$ & 17.6 & 29.5 & 52.9 \\
\hline Behavior Regulation Index & 17 & $67.41(15.67)$ & $50(10)$ & +17.41 & $\mathrm{t}(16)=4.58$ & $<.001$ & 29.4 & 23.5 & 47.1 \\
\hline Metacognition Index & 17 & $71.12(13.39)$ & $50(10)$ & +21.12 & $\mathrm{t}(16)=6.5$ & $<.001$ & 23.5 & 17.7 & 58.8 \\
\hline & & & & & & \multicolumn{2}{|c|}{ Average or above } & \multicolumn{2}{|c|}{ Below average } \\
\hline \multicolumn{10}{|c|}{ Behavior, parent ratings (SDQ) } \\
\hline Total score & 25 & $\operatorname{Mdn}=15$ & $8.2(6.1)$ & +6.32 & $\mathrm{Z}=302$ & $<.001$ & 52 & \multicolumn{2}{|c|}{48} \\
\hline \multicolumn{10}{|c|}{ Behavior, teacher ratings (SDQ) } \\
\hline Total score & 16 & $13.25(7.19)$ & $6.5(6)$ & +6.75 & $t(15)=3.76$ & .002 & 56.3 & \multicolumn{2}{|c|}{43.8} \\
\hline \multicolumn{10}{|c|}{ Social functioning, parent ratings (SSIS) } \\
\hline Social Skills & 22 & $86.95(20.8)$ & $100(15)$ & -13.05 & $t(21)=-2.94$ & .008 & 59.1 & \multicolumn{2}{|c|}{40.9} \\
\hline Problem Behaviors & 22 & $104(14.71)$ & $100(15)$ & +4 & $\mathrm{t}(21)=5.32$ & $<.001$ & 31.8 & \multicolumn{2}{|c|}{68.2} \\
\hline Autism Spectrum & 22 & & & & & & 38.1 & \multicolumn{2}{|c|}{61.9} \\
\hline \multicolumn{10}{|c|}{ Social functioning, teacher ratings (SSIS) } \\
\hline Social Skills & 18 & $90(17.67)$ & $100(15)$ & -10 & $t(17)=-2.4$ & .028 & 94.4 & \multicolumn{2}{|c|}{5.6} \\
\hline Problem Behaviors & 18 & $111(11.77)$ & $100(15)$ & +11 & $t(17)=3.97$ & $<.001$ & 66.7 & \multicolumn{2}{|c|}{33.3} \\
\hline Autism Spectrum & 18 & & & & & & 44.4 & \multicolumn{2}{|c|}{55.6} \\
\hline
\end{tabular}


Note: Average or above $=$ scores $>-1$ standard deviation $(S D)$ of the test mean, Mild impairment $=$ scores $\leq-1$ to $<-2$ SD, Moderate to severe impairment $=$ scores $\leq-2 S D$. The number of cases differs for each outcome as not all informants provided responses for each measure. WASI, WISC-IV, WRAT-4 higher scores reflect better performance. BRIEF and SDQ: lower scores reflect better functioning. SSIS: higher scores on the Social Skills scale indicates better functioning, while lower scores on the Problem Behavior scale indicates better functioning.

Abbreviations: WASI: Wechsler Abbreviated Intelligence Scale; WISC-IV: Wechsler Intelligence Scale for Children, 4th edition; WRAT-4: Wide Range Achievement Test 4; BRIEF: Behavioral Rating Inventory of Executive Function; SDQ: Strengths and Difficulties Questionnaire; SSIS: Social Skills Improvement System. 
Table 3. Risk factors significantly associated with neuropsychological outcomes in children with AgCC

\begin{tabular}{|c|c|c|c|c|c|c|}
\hline & Risk Factor (Predictor) & $\mathbf{B}$ & $\begin{array}{l}\text { Standard Error } \\
\text { B }\end{array}$ & $r^{2}$ & $\beta$ & $\mathbf{p}$ \\
\hline \multicolumn{7}{|c|}{ General intellectual functioning (WASI or WISC-IV) } \\
\hline Full-Scale IQ & none & & & & & \\
\hline Verbal IQ & none & & & & & \\
\hline Performance IQ & none & & & & & \\
\hline \multicolumn{7}{|c|}{ Academic functioning (WRAT-4) } \\
\hline \multirow[t]{2}{*}{ Word Reading } & Social Risk Index* & -5.08 & 1.9 & & -.53 & $.006^{*}$ \\
\hline & AgCC type & 16.27 & 6.9 & .362 & .41 & .028 \\
\hline Spelling & Social Risk Index & -3.83 & 1.43 & .221 & -.47 & .015 \\
\hline \multirow{2}{*}{ Math Computation } & Social Risk Index* & -3.48 & .97 & & -.55 & $.001^{*}$ \\
\hline & CNS anomalies & -11.81 & 4.33 & .442 & -.41 & .012 \\
\hline \multicolumn{7}{|c|}{ Executive functioning in daily life, parent ratings (BRIEF) } \\
\hline \multirow[t]{3}{*}{ Behavior Regulation Index } & Social Risk Index* & 3.45 & .95 & .501 & .53 & $.001 *$ \\
\hline & AgCC type* & -14.221 & 4.41 & & -.51 & $.004 *$ \\
\hline & Age at testing & 2.432 & .96 & & .4 & .018 \\
\hline Metacognition Index & Social Risk Index* & 2.53 & .78 & .259 & .54 & $.002 *$ \\
\hline Global Executive & Social Risk Index* & 3.14 & .77 & & .57 & $<.001^{*}$ \\
\hline \multirow[t]{2}{*}{ Composite } & AgCC type* & -10.98 & 3.57 & & -.47 & $.005^{*}$ \\
\hline & Age at testing & 2.1 & .77 & .534 & .41 & .012 \\
\hline \multicolumn{7}{|c|}{ Executive functioning in daily life, teacher ratings (BRIEF) } \\
\hline \multirow[t]{2}{*}{ Behavior Regulation Index } & Seizure disorder & -22 & 8.05 & & -.61 & .016 \\
\hline & CNS anomalies & -15.25 & 7.5 & .385 & -.46 & .061 \\
\hline Metacognition Index & none & & & & & \\
\hline Global Executive & Seizure disorder & -18.5 & 7.12 & & -.44 & .021 \\
\hline Composite & CNS anomalies & -12.8 & 6.6 & .361 & -.6 & .074 \\
\hline \multicolumn{7}{|c|}{ Behavior, parent ratings (SDQ) } \\
\hline Total score & Social Risk Index* & 2.28 & .43 & .555 & .75 & $<.001^{*}$ \\
\hline \multicolumn{7}{|c|}{ Behavior, teacher ratings (SDQ) } \\
\hline Total score & CNS anomalies* & -10.11 & 2.97 & .453 & -.67 & $.004 *$ \\
\hline \multicolumn{7}{|c|}{ Social functioning, parent ratings (SSIS) } \\
\hline \multirow[t]{2}{*}{ Social Skills } & Social Risk Index & -3.81 & 1.38 & & -.434 & .013 \\
\hline & Genetic disorder & 19.15 & 7.76 & & .4 & .024 \\
\hline Problem Behaviors & none & & & & & \\
\hline \multicolumn{7}{|c|}{ Social functioning, teacher ratings (SSIS) } \\
\hline Social Skills & CNS anomalies & 18.5 & 7.85 & .258 & .51 & .031 \\
\hline
\end{tabular}


Notes: Sex had a significant impact on SSIS parent ratings and therefore sex was entered as a covariate in regression analyses. Risk factors that reached significance at the Bonferroni-corrected level $(p<.006)$ are indicated with *.

Abbreviations: AgCC agenesis of the corpus callosum. CNS central nervous system. WASI Wechsler Abbreviated Intelligence Scale. WISC-IV Wechsler Intelligence Scale for Children, 4th edition. WRAT-4 Wide Range Achievement Test 4. BRIEF Behavioral Rating Inventory of Executive Function. SDQ Strengths and Difficulties Questionnaire. SSIS Social Skills Improvement System.

Backward hierarchical regressions examined risk factors as predictors of each outcome, including: age at testing, social risk index, AgCC type (complete vs partial), size of the anterior and of the posterior commissures (absent, reduced, normal or enlarged), additional CNS anomalies, diagnosed genetic condition, and seizure disorder. 
Supplementary table. Clinical characteristics and MRI findings of children and adolescents with AgCC included in the study

\begin{tabular}{|c|c|c|c|c|c|c|c|c|c|c|c|c|c|c|c|}
\hline$I D$ & Age & Sex & $H$ & Education & Help & FSIQ & $P / C$ & CC status & $A C$ & $P C$ & $P B$ & $\mathrm{CO}$ & Additional MRI findings & Seizures & Genetic \\
\hline 001 & 15.67 & $\mathrm{~F}$ & $\mathrm{~L}$ & Mainstream & + & 81 & $\mathrm{C}$ & CC absent & ++ & ++ & + & + & $\begin{array}{l}\text { Bilateral periventricular } \\
\text { nodular heterotopia }\end{array}$ & + & $\begin{array}{l}+ \\
\text { FLNA gene }\end{array}$ \\
\hline 002 & 14.33 & $\mathrm{~F}$ & $\mathrm{R}$ & Special & & 40 & $\mathrm{P}$ & $\begin{array}{l}\text { Presence of a thin } \\
\text { middle posterior body } \\
\text { and posterior body }\end{array}$ & tiny & tiny & + & - & $\begin{array}{l}\text { (a) irregular crowded } \\
\text { sulci posteriorly in the } \\
\text { occipital region and } \\
\text { medial parasaggital } \\
\text { region (b) shunt: enter R } \\
\text { post-parietal region going } \\
\text { into R lateral ventricle (c) } \\
\text { bilateral periventricular } \\
\text { nodules heterotopia = } \\
\text { frontal predominant, } \\
\text { lining frontal horns and } \\
\text { mid bodies of lateral } \\
\text { ventricles }\end{array}$ & - & - \\
\hline 003 & 11.75 & M & $\mathrm{L}$ & Mainstream & + & 96 & $\mathrm{P}$ & $\begin{array}{l}\text { Presence of part of the } \\
\text { genu }\end{array}$ & + & + & + & + & None & - & - \\
\hline 007 & 14.75 & $\mathrm{~F}$ & $\mathrm{~L}$ & Special & & 69 & $\mathrm{P}$ & $\begin{array}{l}\begin{array}{l}\text { Presence of } \\
\text { rostrum, genu, }\end{array} \\
\text { anterior body }\end{array}$ & + & + & - & - & $\begin{array}{l}\text { Agenesis of the septum } \\
\text { pellucidum, semilobar } \\
\text { holoprosencephaly }\end{array}$ & + & - \\
\hline 008 & 8.33 & M & $\mathrm{L}$ & $\begin{array}{l}\text { Mainstream } \\
\& \\
\text { Special }\end{array}$ & + & 73 & $\mathrm{C}$ & CC absent & + & + & + & + & Cortical dysplasia & - & - \\
\hline 010 & 9.67 & M & $\mathrm{L}$ & Mainstream & + & 62 & $\mathrm{P}$ & Presence of the rostrum & tiny & + & - & + & None & - & - \\
\hline 011 & 11.67 & M & $\mathrm{L}$ & Mainstream & + & 75 & $\mathrm{C}$ & CC absent & + & + & + & + & None & - & - \\
\hline 012 & 15.33 & $\mathrm{~F}$ & $\mathrm{R}$ & Mainstream & - & 100 & $\mathrm{P}$ & Presence of the rostrum & ++ & + & + & + & $\begin{array}{l}\text { Bilateral periventricular } \\
\text { heterotopic grey matter }\end{array}$ & + & - \\
\hline 013 & 9.50 & M & $\mathrm{L}$ & Mainstream & - & 81 & $\mathrm{P}$ & $\begin{array}{l}\text { Presence of the rostrum } \\
\text { and of the genu }\end{array}$ & + & + & - & - & $\begin{array}{l}\text { Cerebellar hemispheric } \\
\text { hypoplasia, Dandy } \\
\text { Walker variant, } \\
\text { Heterotopic grey matter, } \\
\text { small interhemispheric } \\
\text { cyst }\end{array}$ & - & - \\
\hline 015 & 10.25 & $\mathrm{~F}$ & $\mathrm{~L}$ & Mainstream & - & 73 & $\mathrm{P}$ & $\begin{array}{l}\text { Presence of the middle- } \\
\text { posterior body, } \\
\text { posterior body, and the } \\
\text { splenium }\end{array}$ & + & + & - & - & $\begin{array}{l}\text { Abormal grey matter } \\
\text { around the frontal horns } \\
\text { of the lateral ventricles, } \\
\text { abnormal sulci medio in } \\
\text { frontal lobe }\end{array}$ & + & - \\
\hline
\end{tabular}




\begin{tabular}{|c|c|c|c|c|c|c|c|c|c|c|c|c|c|c|c|}
\hline 016 & 13.42 & $\mathrm{~F}$ & $\mathrm{R}$ & Mainstream & - & 93 & $\mathrm{P}$ & $\begin{array}{l}\text { Presence of the anterior } \\
\text { body }\end{array}$ & tiny & ++ & + & - & None & - & - \\
\hline 017 & 8.83 & $\mathrm{~F}$ & $\mathrm{R}$ & Special & - & 71 & $\mathrm{C}$ & $\mathrm{CC}$ absent & tiny & + & + & + & $\begin{array}{l}\text { Bilateral periventicular } \\
\text { heterotopic grey matter }\end{array}$ & - & - \\
\hline 018 & 12 & M & $\mathrm{R}$ & $\begin{array}{l}\text { Mainstream } \\
\text { Special } \\
\text { (high } \\
\text { school) }\end{array}$ & + & 72 & $\mathrm{C}$ & $\mathrm{CC}$ absent & + & + & + & + & None & - & + \\
\hline 019 & 8.58 & M & $\mathrm{R}$ & Mainstream & + & 73 & $\mathrm{C}$ & $\mathrm{CC}$ absent & + & tiny & + & + & None & - & $\begin{array}{l}+ \\
\text { dup } 3 p 26.3\end{array}$ \\
\hline 020 & 12.67 & M & $\mathrm{L}$ & Mainstream & + & 76 & $\mathrm{C}$ & $\mathrm{CC}$ absent & tiny & tiny & + & - & $\begin{array}{l}\text { Abnormal deep sulcation } \\
\text { (right parietal) lined by } \\
\text { polymicrogyria }\end{array}$ & - & - \\
\hline 021 & 10.67 & M & $\mathrm{R}$ & Special & - & 84 & $\mathrm{C}$ & $\mathrm{CC}$ absent & ++ & ++ & + & + & $\begin{array}{l}\text { Unilateral periventricular } \\
\text { heterotopic grey matter } \\
\text { (right frontal horn) }\end{array}$ & - & - \\
\hline 024 & 10.83 & M & $\mathrm{R}$ & Mainstream & + & 82 & $\mathrm{C}$ & $\mathrm{CC}$ absent & ++ & + & + & + & None & - & - \\
\hline 025 & 12.58 & M & $\mathrm{R}$ & $\begin{array}{l}\text { Mainstream } \\
\text { Special } \\
\text { (high } \\
\text { school) }\end{array}$ & + & 74 & $\mathrm{P}$ & $\begin{array}{l}\text { Presence of the middle- } \\
\text { posterior body, } \\
\text { posterior body, and the } \\
\text { splenium }\end{array}$ & + & + & - & + & $\begin{array}{l}\text { Right schizencephaly, } \\
\text { polymicrogyria }\end{array}$ & - & - \\
\hline 026 & 14.83 & $\mathrm{~F}$ & $\mathrm{R}$ & Mainstream & - & 70 & $\mathrm{P}$ & $\begin{array}{l}\text { Presence of the } \\
\text { rostrum, genu, anterior } \\
\text { body, and a thin middle } \\
\text { anterior body }\end{array}$ & + & tiny & - & - & Bilateral polymicrogyria & - & - \\
\hline 107 & 11.58 & M & $\mathrm{L}$ & Mainstream & + & 66 & $\mathrm{C}$ & $\mathrm{CC}$ absent & ++ & ++ & + & + & $\begin{array}{l}\text { Left interhemispheric } \\
\text { cyst, hypoplasia of the } \\
\text { left cerebral hemisphere. }\end{array}$ & - & - \\
\hline 108 & 10.17 & M & $\mathrm{L}$ & $\begin{array}{l}\text { Montesori } \\
\text { School }\end{array}$ & + & 83 & $\mathrm{C}$ & $\mathrm{CC}$ absent & + & + & + & - & $\begin{array}{l}\text { Left interhemispheric } \\
\text { cyst, grey matter } \\
\text { heterotopia, left anterior } \\
\text { hemispheric cortical } \\
\text { dysplasia }\end{array}$ & - & - \\
\hline 109 & 9.67 & $\mathrm{~F}$ & $\mathrm{R}$ & Mainstream & - & 126 & $\mathrm{P}$ & $\begin{array}{l}\text { Presence of a thin } \\
\text { rostrum, genu and } \\
\text { anterior body }\end{array}$ & + & + & + & + & $\begin{array}{l}\text { None } \\
\text { (history of haemorrhagic } \\
\text { cerebral AVM } \\
\text { (due to genetic } \\
\text { condition)) }\end{array}$ & - & $\begin{array}{l}+ \\
\text { Hereditary } \\
\text { haemorrhagic } \\
\text { telangectasia }\end{array}$ \\
\hline 110 & 9 & M & $\mathrm{L}$ & Mainstream & - & 95 & $\mathrm{C}$ & $\mathrm{CC}$ absent & + & + & + & + & $\begin{array}{l}\text { Interhemispheric cyst } \\
\text { with saptation in the left } \\
\text { hemisphere, causing } \\
\text { pressure in the right. }\end{array}$ & - & - \\
\hline
\end{tabular}




\begin{tabular}{|c|c|c|c|c|c|c|c|c|c|c|c|c|c|c|c|}
\hline & & & & & & & & & & & & & $\begin{array}{l}\text { Cortex around the cyst is } \\
\text { malformed }\end{array}$ & & \\
\hline 112 & 17.08 & M & $\mathrm{R}$ & Mainstream & + & 82 & $\mathrm{P}$ & Presence of the rostrum & - & + & + & + & $\begin{array}{l}\text { Frontonasl dysplasia, } \\
\text { sphenoidal } \\
\text { encephalocele, non } \\
\text { visualization of the } \\
\text { pituitary gland }\end{array}$ & - & - \\
\hline 113 & 10 & $\mathrm{~F}$ & $\mathrm{R}$ & Mainstream & + & 73 & C & $\mathrm{CC}$ absent & + & + & + & + & None & - & - \\
\hline 022 & 8.67 & $\mathrm{~F}$ & M & $\begin{array}{l}\text { Mainstream } \\
\& \\
\text { Special }\end{array}$ & + & 71 & $\mathrm{C}$ & $\mathrm{CC}$ absent & + & ++ & + & - & $\begin{array}{l}\text { Unusual deep sulci (right } \\
\text { central sulcus, } \\
\text { parasagittal region } \\
\text { posteriorly) }\end{array}$ & - & $\begin{array}{l}+ \\
\text { Oro facial } \\
\text { digital } \\
\text { syndrome } \\
\text { Type } 1\end{array}$ \\
\hline 009 & 12.25 & $\mathrm{~F}$ & M & Special & & $\mathrm{PIQ}=59$ & $\mathrm{P}$ & $\begin{array}{l}\text { Presence of the genu, } \\
\text { anterior and middle } \\
\text { anterior body }\end{array}$ & + & + & + & - & None & - & - \\
\hline 114 & 10.92 & M & $\mathrm{R}$ & Mainstream & + & 73 & $\mathrm{P}$ & $\begin{array}{l}\text { Presence of rostrum, } \\
\text { genu, anterior and } \\
\text { middle anterior body }\end{array}$ & - & + & + & - & None & - & $\stackrel{+}{\text { del } 16 p 13.11}$ \\
\hline
\end{tabular}

Abbreviations: Age (in years); Sex: F female, $M$ male; $H$ Handedness: L left, $R$ right, A ambidextrous; Help: Intervention and remedial support at school; P/C: $P$ partial AgCC, $C$ complete AgCC; CC details: corpus callosum structural properties details; AC: anterior commissure, - absent, + present and normal size, ++ enlargement; PC: Posterior commissure, - absent, + present and normal size, ++ enlargement; PB: probst bundles + present, - absent; CO: colpocephaly + present, - absent; MRI finding: other MRI findings; Seizure + present, - absent; Genetic: Genetic condition or syndrome + present, - absent 